\title{
Collaborative School Leadership A Critical Guide
}

\author{
Philip A Woods and Amanda Roberts
}

Published by SAGE

https://uk.sagepub.com/en-gb/eur/collaborative-school-leadership/book253212

Schools need to respond to rising expectations and the imperative to release the creativity of educators and learners to achieve more socially just education. Yet, strongly hierarchical structures and reliance on the idea of 'great' leaders are persistent features of much school education. This book offers an alternative vision of leadership.

Collaborative leadership as we examine it in the book is a deeper conception than the idea of distributed leadership that is often applied or studied. We see collaborative leadership as both emerging from the perpetual process of complex interactions across the school involving not only school leaders but teachers, support staff, students and others (hence as emergent), and shaped by individual intentions which express meaning, purpose and goals and the will to make a difference (hence as the product of intentionality). Our concept of collaborative leadership draws attention to both the context that gives rise to leadership and the human sparks of creativity and freedom generated by teachers, students and others as they work together.

A clear-eyed view of the purpose and values of leadership as a distributed or shared process is essential to the creation of such creativity and freedom. The book argues that integral to a desirable conception of collaborative leadership is an explicit value-base - a philosophy of co-development rather than dependence. It explains how collaborative leadership practices can be guided by co-development values, where progress is achieved with and by helping others as co-creators of the learning environment of the school. The practical process of developing collaborative leadership is explored through ideas on reciprocal learning, values clarification, reframing leadership and collective identity construction.s

Our discussion of collaborative leadership provides an understanding of leadership that is both analytically robust and ethically explicit. The ideas of intentionality, emergence and the philosophy of co-development are a crucial aid in developing distributed leadership practice, through teacher leadership, for example, that is more collaborative, innovative, critically reflexive and capable of advancing social justice.

This book will be of use to anyone who is interested in exploring critical perspectives of distributed leadership and related concepts such as shared leadership. It offers catalysts for the practical exploration and development of leadership and will be a resource and inspiration to those who seek to promote such exploration and development within their organisation. 